\title{
FATORES CRÍTICOS DE SUCESSO DO ECOSSISTEMA DE INOVAÇÃO: UMA META-SÍNTESE SOBRE A PARTICIPAÇÃO DE UNIVERSIDADES
}

\section{CRITICAL SUCCESS FACTORS OF INNOVATION ECOSYSTEM: A META- SYNTHESIS ON UNIVERSITY PARTICIPATION}

\author{
Tatiane Pereira Librelato* E-mail: tlibrelato@unisinos.br \\ Daniel Pacheco Lacerda* E-mail: dlacerda@unisinos.br \\ *Universidade do Vale do Rio dos Sinos (UNISINOS), São Leopoldo, RS, Brasil
}

\begin{abstract}
Resumo: Há vários atores que participam de um ecossistema de inovação, entre eles as Universidades empreendedoras (YAGHMAIE; VANHAVERBEKE, 2019). Entretanto, os modelos de implementação da universidade empreendedora são incompletos e na literatura há poucos esforços que buscam mapear e planejar as demandas para que universidade se torne parte de um ecossistema de inovação. (DE MOURA et al., 2019). Diante deste contexto, esta pesquisa se propõe a identificar quais são os fatores críticos de sucesso para implementação da universidade empreendedora na visão da comunidade científica brasileira. A partir de uma revisão sistemática da literatura, foi conduzida uma meta-síntese qualitativa sobre universidades no contexto dos ecossistemas de inovação por meio do Literature Grounded Theory (LGT). Além do mapeamento da literatura, os resultados identificam os fatores críticos de sucesso para participação de universidades em ecossistemas de inovação. Tais fatores tem em sua origem relações de causa e efeito que puderam ser descobertas por meio da identificação de regras de associação entre os estudos analisados, o que até então, não havia sido mapeado na literatura. A partir desta análise as universidades podem identificar as demandas e planejar as ações estratégicas para criação, inserção ou adequação, bem como rever seu modelo de atuação em ecossistemas de inovação.
\end{abstract}

Palavras-chave: Ecossistemas de inovação. Universidade empreendedora. Fatores críticos de Sucesso.

\begin{abstract}
There are several actors that participate in an innovation ecosystem, among them the Entrepreneurial Universities (YAGHMAIE; VANHAVERBEKE, 2019). However, the implementation models of the entrepreneurial university are incomplete and in the literature there are few efforts that seek to map and plan the demands for the university to become part of an innovation ecosystem. (DE MOURA, et al., 2019). Faced with this context, this research aims to identify what are the critical success factors for the implementation of the entrepreneurial university in the view of the Brazilian scientific community. Based on a systematic review of the literature, a qualitative meta-synthesis on universities in the context of innovation ecosystems was conducted through the Literature Grounded Theory (LGT). The results identify the critical success factors for university participation in innovation ecosystems. Such factors have in their origin cause and effect relationships that could be discovered through the identification of association rules between the analyzed studies, which until then, had not been mapped in the literature. Based on this analysis, universities can identify the demands and plan strategic actions for creation, insertion or adaptation, as well as review their model of action in innovation ecosystems.
\end{abstract}

Keywords: Innovation Ecosystem. Entrepreneurial university. Critical Success Factors. 


\section{INTRODUÇÃO}

Ecossistema de inovação (EI) é um tema relativamente novo (YAGHMAIE; VANHAVERBEKE, 2019), emergente (SHAW; ALLEN, 2016) e que tem se desenvolvendo rapidamente. Embora as descrições apresentadas ainda sejam vagas (AUDRETSCH et al., 2019), surgiram como um contexto importante para o empreendedorismo (NAMBISAN; BARON, 2013), contando com a participação de vários atores (HAYTER, 2016). Dentre tais atores encontram-se as universidades que, no contexto ecossistêmico, são denominadas Universidades Empreendedoras (UEs).

Embora as UEs sejam consideradas um ator importante no El, estudos tradicionais tendem a apresentar uma visão estreita das relações indústriauniversidade (GUERRERO et al., 2016). No contexto ecossistêmico, as UEs assumem relevância no desenvolvimento econômico de uma região. Tal desenvolvimento pode ser fomentado por meio da colaboração entre governo, indústria e universidade - a tripla hélice. (AUDRETSCH et al., 2019; ETZKOWITZ; LEYDESDORFF, 2000). Assim, as UEs agregam valor aos processos de desenvolvimento regional e ancoram o conhecimento no EI (AUDRETSCH et al., 2019). Entretanto, a literatura sugere a necessidade de estudos que explorem o papel das universidades no El. (PEDRINHO et al., 2020).

Políticas governamentais para fomentar o surgimento e a consolidação de Els e de mecanismos de geração de empreendimentos inovadores foram instituídas no Brasil por meio da Política Nacional de Inovação-PNI. Entretanto, na literatura há poucos esforços que buscam mapear e planejar as demandas para que universidade se torne parte de um El. (DE MOURA, et.al., 2019).

Assim, se por um lado, a universidade é considerada um ator importante do ecossistema de inovação e espera-se que a se torne o principal vínculo entre os demais atores (GUERRERO et al., 2016), por outro lado, os modelos de implementação da UEs são incompletos. Desta forma, há chances reais de que elementos importantes sejam ignorados ou deixados em segundo plano, inviabilizando a implementação da UE como estratégia de negócio, tornando a criação de valor no El insuficiente e prejudicando a captação e apropriação de valor pelos membros do ecossistema. 
Diante do interesse do governo em viabilizar os Els por meio de uma PNI, do interesse das universidades como atores destes ecossistemas e do interesse da sociedade em geral no que tange ao desenvolvimento regional, esta pesquisa se se propõe a identificar quais são os fatores críticos de sucesso para implementação da universidade empreendedora na visão da comunidade científica brasileira. Para responder a questão de pesquisa foram definidos como objetivos deste estudo: i) mapear e analisar os estudos conduzidos pela comunidade científica nacional; ii) identificar e definir os fatores críticos de sucesso para implementação da UE. As principais contribuições consistem na identificação e análise das relações ocultas de causa e efeito por meio das regras de associação. Foram identificadas 8 regras de associação e 28 fatores críticos de sucesso que devem ser considerados para universidades obterem sucesso no contexto de El. A partir desta análise as UEs podem identificar as demandas e planejar as ações estratégicas para criação, inserção ou adequação, bem como rever seu modelo de atuação no El.

Esta pesquisa está estruturada em 6 sessões. Além da introdução, que aborda a contextualização deste estudo, a sessão 2 aborda os principais conceitos que suportam a análise proposta. A sessão 3 apresenta a metodologia para condução da pesquisa. A sessão 4 apresenta os resultados encontrados, que são discutidos na sessão 5 . Por fim, a sessão 6 apresenta as considerações finais e indicações de estudos futuros.

\section{ECOSSISTEMA DE INOVAÇÃO - EI}

Ecossistema de inovação é um tema emergente que tem se desenvolvido rapidamente (AUDRETSCH et al., 2019). Na literatura identifica-se diversas tentativas de conceituar El. Alguns estudos abordam o conceito a partir da biologia. (MOORE, J. F., 1993). Outros relacionam à criação de valor. (MOORE, G. A., 1991). Nambisan e Baron (2013) abordam o conceito associado a governança e ao papel dos orquestradores, enquanto Adner (2006) e Yaghmaie; Vanhaverbeke (2019) relacionam com a inovação aberta. Clarysse et al., (2014) e Hayter (2016) abordam a temática a partir da interação do conhecimento com a dinâmica local das atividades de negócios, criação de conhecimento e inovação em sí. Entretanto, por tratar-se de uma temática relativamente recente, ainda não há consenso na 
academia que permita a proposição de um conceito universalmente aceito. (YAGHMAIE; VANHAVERBEKE, 2019).

Uma característica fundamental do El diz respeito à sua capacidade de evoluir ao longo do tempo. Esse processo envolve tanto a geração de novos agentes, por meio do empreendedorismo impulsionado pela inovação, quanto a atração de novas empresas. (FISCHER; SCHAEFFER; SILVEIRA, 2018). O tamanho de um ecossistema e a heterogeneidade dos parceiros geram dinâmicas ausentes nos acordos um-a-um, como na inovação aberta (YAGHMAIE; VANHAVERBEKE, 2019). Diferem ainda dos mercados tradicionais, pois são caracterizados por cooperação em rede e compartilhamento de resultados (AUDRETSCH et al., 2019). Assim, no contexto ecossistêmico, as características e resultados coletivos tornam-se maior que características e resultados de suas partes individuais.

\subsection{Ecossistema de inovação e universidade no Brasil}

No contexto ecossistêmico, a universidade é denominada universidade empreendedora (UE). (YAGHMAIE; VANHAVERBEKE, 2019). Em estudos tradicionais, as universidades empreendedoras são consideradas o principal ator ou vínculo entre todos os demais atores envolvidos (GUERRERO et al., 2016), ancorando a importância do conhecimento no El. (MARKKULA, MARKKU; KUNE, 2015). A UE é uma organização que adota um estilo de gestão empresarial conjuntamente com seus membros (professores, estudantes e funcionários) e que interage internamente com seu ambiente externo (comunidade / região) agindo de forma empreendedora (GUERRERO et al., 2016). Devido à sua capacidade de criar, difundir e implantar conhecimentos economicamente úteis, o papel da UE está associado ao contexto econômico, sendo compreendida como um agente central nesses ecossistemas. (CLARYSSE et al., 2014; GUERRERO et al., 2016).

No Brasil, políticas governamentais para fomentar o surgimento e a consolidação de ecossistemas de inovação e de mecanismos de geração de empreendimentos inovadores no País foram instituídas. A Lei no 13243/2016, conhecida como Marco Legal de Ciência, Tecnologia e Inovação, regulamenta tais ligações e favorece a criação de um ambiente mais favorável à pesquisa e inovação 
no País. De forma complementar, a Portaria MCTIC no 6.762, de 17.12.2019 institui o Programa Nacional de Apoio aos Ambientes Inovadores - PNI, que estabelece regras mais claras para a participação de acadêmicos em projetos internos das empresas, bem como o uso compartilhado de laboratórios e outras instalações de pesquisa.

Por meio do estímulo e fortalecimento da cooperação nacional (local e regional) e internacional entre os agentes de inovação e os ambientes promotores da inovação, o principal objetivo de tais políticas é o desenvolvimento e impulsionamento da inovação e capacidade competitiva brasileira em âmbito global. Entretanto, barreiras burocráticas e riscos de apropriação da propriedade intelectual para empresas envolvidas em projetos colaborativos ainda permanecem desafiadores (FISCHER; SCHAEFFER; SILVEIRA, 2018).

Os impactos dessa estrutura em evolução não são imediatos. Com a passagem do tempo, os Els podem afetar positivamente as tendências evolutivas dos vínculos entre a academia e a indústria, fortalecendo o papel das universidades como fator de atração para estratégias de localização de negócios. (FISCHER; SCHAEFFER; SILVEIRA, 2018).

\section{PROCEDIMENTOS METODOLÓGICOS}

Para responder ao problema de pesquisa, foi elaborado uma revisão sistemática da literatura aplicando a estratégia de condução Literature Grounded Theory - LGT, proposto por Ermel (2020). A figura 1 apresenta as etapas do LGT combinada com o método de trabalho, bem como as principais saídas de cada etapa. 
Figura 1 - Procedimentos metodológicos

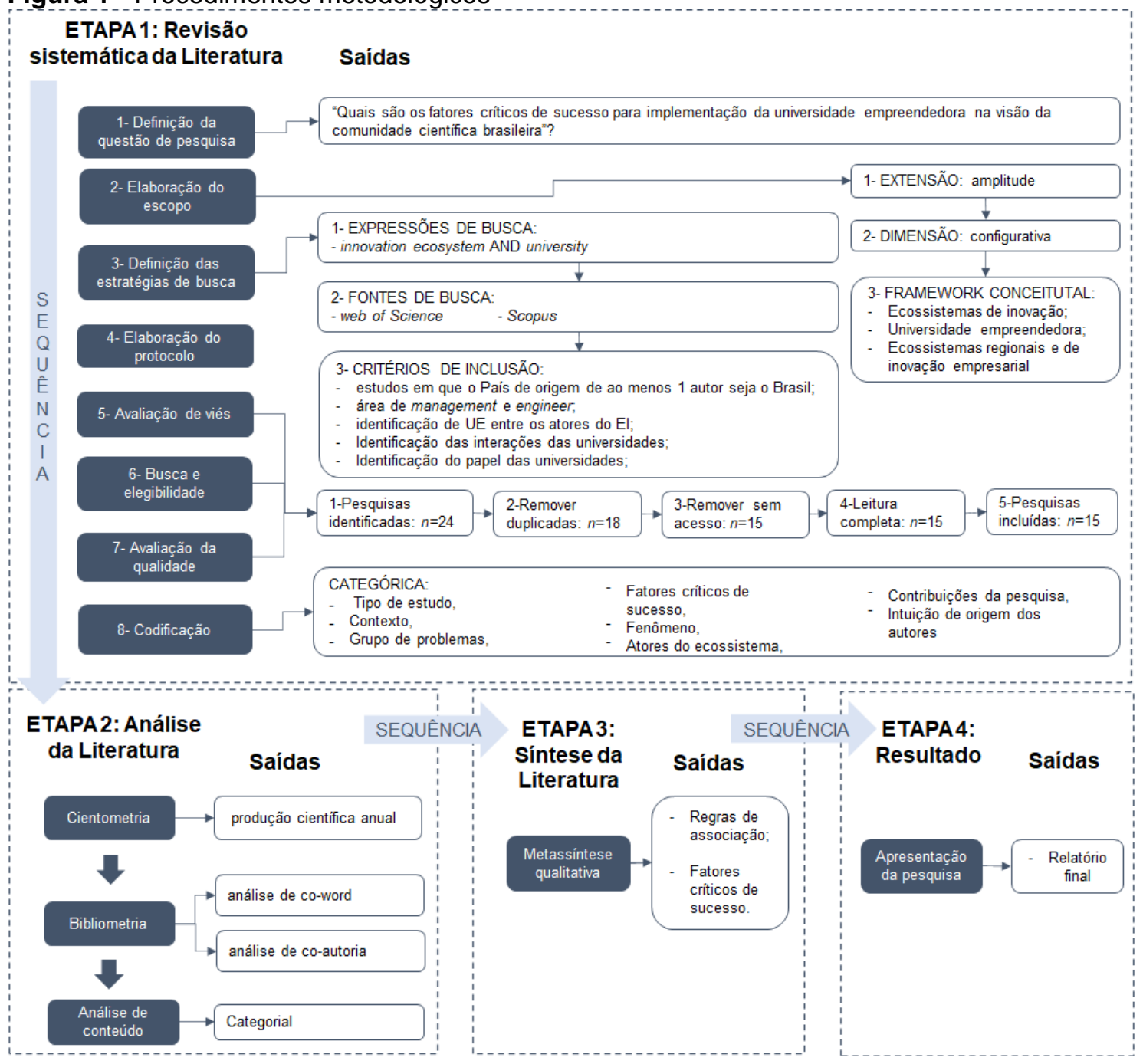

Fonte: Autores (2020)

A Figura 1 apresenta a sequência de etapas seguida por esta pesquisa. Um protocolo prévio foi elaborado, alinhado com as recomendações de Morandi; Camargo (2015). A Figura 2 apresenta o protocolo seguido por esta pesquisa. 
Figura 2 - Protocolo para revisão sistemática da literatura

\begin{tabular}{|c|c|c|}
\hline \multicolumn{3}{|c|}{ PROTOCOLO PARA REVISÄO SISTEMÁTICA DA LITERATURA } \\
\hline \multicolumn{2}{|c|}{ Questão de interesse: } & $\begin{array}{l}\text { Quais são os fatores críticos de sucesso para implementação da } \\
\text { universidade empreendedora na visão da comunidade científica } \\
\text { brasileira. }\end{array}$ \\
\hline \multicolumn{2}{|c|}{$\begin{array}{l}\text { Escopo da revisão - extensão } \\
\text { da revisão: }\end{array}$} & $\checkmark$ Amplitude \\
\hline \multicolumn{2}{|c|}{ Estratégia de revisão: } & $\begin{array}{l}\square \text { Agregativa } \\
\square \text { Configurativa }\end{array}$ \\
\hline \multicolumn{2}{|c|}{ Framework conceitual: } & Ecossistemas de Inovação; universidade; \\
\hline \multicolumn{2}{|c|}{ Horizonte de tempo: } & Sem definição a priori \\
\hline \multicolumn{2}{|c|}{ Idiomas: } & Português e inglês \\
\hline \multirow[b]{3}{*}{$\begin{array}{l}\text { Estratégias de } \\
\text { busca: }\end{array}$} & $\begin{array}{l}\text { Expressões } \\
\text { de busca: }\end{array}$ & $\begin{array}{l}\text { - innovation ecosystem AND university } \\
\text { - ecossistema de inovação e universidade }\end{array}$ \\
\hline & $\begin{array}{l}\text { Fontes de } \\
\text { busca: }\end{array}$ & $\begin{array}{l}\text { - web of science } \\
\text { - Scopus }\end{array}$ \\
\hline & $\begin{array}{l}\text { Critérios de } \\
\text { inclusão: }\end{array}$ & $\begin{array}{l}\text { Inclusão - estudos de revisão de literatura da área de management e } \\
\text { engineer que abordem: } \\
\text { - identificação de modelos de participação de Universidades em } \\
\text { ecossistemas de inovação; } \\
\text { - identificação das expectativas sobre atuação das universidades em } \\
\text { ecossistemas de inovação; }\end{array}$ \\
\hline Coleta de dados & $\begin{array}{l}\text { Categorias de } \\
\text { códigos }\end{array}$ & $\begin{array}{l}\text { Categorização mista (códigos abertos e fechados) apresentadas no } \\
\text { Apêndice C }\end{array}$ \\
\hline \multicolumn{2}{|l|}{ Análise de dados: } & $\begin{array}{l}\text { - Cientometria - produção científica anual; } \\
\text { - Bibliometria - análise de co-word; análise de citações (identificação } \\
\text { dos periódicos que publicaram as pesquisas mais importantes, } \\
\text { identificação dos principais estudos no assunto) e; } \\
\text { - Análise de conteúdo categorial. }\end{array}$ \\
\hline \multicolumn{2}{|l|}{ Síntese de dados: } & $\begin{array}{l}\text { Definição das ferramentas para a síntese da literatura: } \\
\text { - Meta-síntese Qualitativa }\end{array}$ \\
\hline
\end{tabular}

Fonte: Autores (2020)

Conforme apresenta a Figura 2, foram incluídos artigos em conferências e publicações em periódicos. Tal critério justifica-se pelo fato de o tema ser relativamente novo, sendo comum, nestes casos, que estudos apresentados em conferências sejam considerados para análise. Não houve exclusão de estudos pelo critério de elegibilidade devido a natureza desta pesquisa. Assim, excluindo-se estudos duplicados ou que não puderam ser acessados, 15 estudos primários foram selecionados. O Quadro 1 apresenta tais estudos. 
Quadro 1 - Estudos primários selecionados

\begin{tabular}{|c|c|c|c|c|}
\hline Número & Título & Autor (s), ano & $\begin{array}{c}\text { Tipo de } \\
\text { documento }\end{array}$ & $\begin{array}{l}\text { Procedimento } \\
\text { técnico }\end{array}$ \\
\hline 1 & $\begin{array}{l}\text { A Inovação, O Desenvolvimento E O } \\
\text { Papel Da Universidade }\end{array}$ & Audy, J. (2017) & Article & $\begin{array}{c}\text { Pesquisa } \\
\text { bibliográfica }\end{array}$ \\
\hline 2 & $\begin{array}{l}\text { Beyond Education: The Role Of } \\
\text { Research Universities In Innovation } \\
\text { Ecosystems }\end{array}$ & $\begin{array}{l}\text { Schaeffer, P.R.; } \\
\text { Fischer, B.; Queiroz } \\
\text { S. (2018) }\end{array}$ & Article & $\begin{array}{l}\text { Estudo de } \\
\text { caso }\end{array}$ \\
\hline 3 & $\begin{array}{l}\text { Collaborative Networks And } \\
\text { Sustainable Business: A Case Study } \\
\text { In The Brazilian System Of } \\
\text { Innovation }\end{array}$ & $\begin{array}{l}\text { Varrichio, et.al. } \\
\text { (2012) }\end{array}$ & $\begin{array}{l}\text { Conference } \\
\text { paper }\end{array}$ & $\begin{array}{l}\text { Estudo de } \\
\text { caso }\end{array}$ \\
\hline 4 & $\begin{array}{l}\text { Entrepreneurial University - A } \\
\text { Method Of Evaluation And Planning } \\
\text { Applied In Brazil }\end{array}$ & $\begin{array}{l}\text { De Moura, et.al. } \\
(2019)\end{array}$ & Article & $\begin{array}{l}\text { Estudo de } \\
\text { caso }\end{array}$ \\
\hline 5 & $\begin{array}{l}\text { From Industrial Cities To Smart } \\
\text { Cities }\end{array}$ & $\begin{array}{l}\text { Zawislak, P.A.; } \\
\text { Pufal, N.A.; } \\
\text { Camboim, G.F. } \\
(2020)\end{array}$ & $\begin{array}{l}\text { Conference } \\
\text { paper }\end{array}$ & $\begin{array}{c}\text { Pesquisa } \\
\text { bibliográfica }\end{array}$ \\
\hline 6 & $\begin{array}{l}\text { Industry } 4.0 \text { Innovation Ecosystems: } \\
\text { An Evolutionary Perspective On } \\
\text { Value Cocreation }\end{array}$ & $\begin{array}{l}\text { Benitez, G.B.; } \\
\text { Ayala, N.F.; Frank, } \\
\text { A.G. }(2020)\end{array}$ & Article & $\begin{array}{l}\text { Estudo de } \\
\text { caso }\end{array}$ \\
\hline 7 & $\begin{array}{l}\text { Innovation Ecosystems In } \\
\text { Engineering Education: From Local } \\
\text { Experiences To A Vision Of The } \\
\text { Future }\end{array}$ & $\begin{array}{l}\text { De Paula, I.C., et.al. } \\
(2017)\end{array}$ & $\begin{array}{l}\text { Conference } \\
\text { paper }\end{array}$ & $\begin{array}{l}\text { Estudo de } \\
\text { caso }\end{array}$ \\
\hline 8 & $\begin{array}{l}\text { Multi-Agent Based Simulation Of } \\
\text { Universities As An Innovation } \\
\text { Ecosystem Based On Knowledge } \\
\text { Flows }\end{array}$ & $\begin{array}{l}\text { Ramos-Filho, et.al. } \\
\text { (2018) }\end{array}$ & $\begin{array}{l}\text { Conference } \\
\text { paper }\end{array}$ & $\begin{array}{l}\text { Estudo de } \\
\text { caso }\end{array}$ \\
\hline 9 & $\begin{array}{l}\text { Socioeconomic Development } \\
\text { Strategies: Innovation Ecosystems } \\
\text { For The Implementation Of Smart } \\
\text { Cities - Case Study In The United } \\
\text { States, China And Sweden }\end{array}$ & $\begin{array}{l}\text { de Oliveira, H.H.N; } \\
\text { de Carvalho, Z.V. } \\
\text { (2017) }\end{array}$ & Article & $\begin{array}{l}\text { Estudo de } \\
\text { caso }\end{array}$ \\
\hline 10 & $\begin{array}{l}\text { Startups And The Innovation } \\
\text { Ecosystem In Industry } 4.0\end{array}$ & $\begin{array}{l}\text { Rocha, C.F.; } \\
\text { Mamédio, D.F.; } \\
\text { Quandt, C.O. (2019) }\end{array}$ & Article & $\begin{array}{l}\text { Estudo de } \\
\text { caso }\end{array}$ \\
\hline 11 & $\begin{array}{l}\text { Strategies And Methodologies For } \\
\text { Civic Engagement And Social } \\
\text { Empowerment (Smart Cities) }\end{array}$ & Santos, et.al. (2018) & $\begin{array}{l}\text { Conference } \\
\text { paper }\end{array}$ & $\begin{array}{l}\text { Estudo de } \\
\text { caso }\end{array}$ \\
\hline 12 & $\begin{array}{l}\text { Universities As Knowledge Flow } \\
\text { Based Innovation Ecosystems }\end{array}$ & $\begin{array}{l}\text { Ramos, J.R.B.; } \\
\text { Lima, C.P. (2018) }\end{array}$ & Article & $\begin{array}{l}\text { Estudo de } \\
\text { caso }\end{array}$ \\
\hline 13 & $\begin{array}{l}\text { Universities' Gravitational Effects On } \\
\text { The Location Of Knowledge- } \\
\text { Intensive Investments In Brazil }\end{array}$ & $\begin{array}{l}\text { Fischer, B.B.; } \\
\text { Schaeffer, P.R.; } \\
\text { Silveira, J.P. (2018) }\end{array}$ & Article & $\begin{array}{l}\text { Estudo de } \\
\quad \text { caso }\end{array}$ \\
\hline 14 & $\begin{array}{l}\text { University And The Innovation } \\
\text { Ecosystem: Structured Literature } \\
\text { Review }\end{array}$ & $\begin{array}{l}\text { Pedrinho, et.al. } \\
(2020)\end{array}$ & Article & $\begin{array}{c}\text { Pesquisa } \\
\text { bibliográfica }\end{array}$ \\
\hline 15 & $\begin{array}{l}\text { Work In Progress: Fostering } \\
\text { Synergy To Create An Innovation } \\
\text { Environment }\end{array}$ & $\begin{array}{l}\text { Valadares, et.al. } \\
(2018)\end{array}$ & $\begin{array}{l}\text { Conference } \\
\text { paper }\end{array}$ & $\begin{array}{l}\text { Estudo de } \\
\text { caso }\end{array}$ \\
\hline
\end{tabular}

Fonte: Autores (2020) 
O Quadro 1 resume os estudos que configuram as unidades de contexto. Foi estabelecido um esquema de codificação misto, apresentado no Apêndice A. Para operacionalizar este processo foi utilizado o software Atlas Ti.

A análise cientométrica analisou dados de produção científica anual para identificar o desenvolvimento do tema no Brasil. Para análise bibliométrica utilizou-se o software VosViewer. As redes utilizadas nesta pesquisa são as redes co-word, que considerou todas as palavras-chave do conjunto de documentos para criar uma estrutura conceitual do campo de pesquisa.

Para a etapa de análise de conteúdo, as unidades registro codificadas foram analisados por meio das regras de associação, correlação e agrupamento. Para operacionalizar este processo foi utilizado o software Rstudio. A síntese da literatura é apresentada por meio da metassíntese a partir de dados qualitativos (DRESCH, A., LACERDA, D. P., JÚNIOR, 2015).

\section{APRESENTAÇÃO DOS RESULTADOS}

Para análise das regras de associação foram selecionados os grupos CT, FN, GP e RS, que atendem ao objetivo da pesquisa. A combinação de códigos resultou em 2.706 variáveis. Foram selecionados apenas estudos que abordam os fenômenos de interesse desta pesquisa. A Figura 3 resume este processo.

Figura 3 - inclusão e exclusão dos fenômenos de interesse e estudos para análise de associação Estudo

\begin{tabular}{|c|c|c|c|c|c|c|c|c|c|c|c|c|c|c|c|c|c|}
\hline \multicolumn{3}{|r|}{ Descrição } & 1 & 2 & 3. & 4 & 56 & $6-7$ & 78 & 9 & 10 & 1 & 12 & 21 & & 4 & 15 \\
\hline \multirow{8}{*}{ 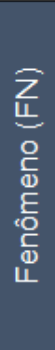 } & FN01 & Contribuições das Startups para inovação digital (4.0) & & & & & & & & & e & & & & & & \\
\hline & FN02 & Desdobramentos da presença das universidades no El & & i & & & & & & & & & & $\mathrm{i}$ & & i & \\
\hline & FN03 & Evolução dos El & & & & & i & & & & & & & & & & \\
\hline & FN04 & Gestão do relacionamento da rede de colaboração do El & & & $\mathrm{i}$ & & & & & & & & & & & & \\
\hline & FN05 & Captação e retenção de alunos no ensino superior & & & & & & & i & i & & & & & & & \\
\hline & FN06 & Inovações disruptivas na educação superior & $\mathrm{i}$ & & & & & i & i & & & & $\mathrm{i}$ & & & & $\mathrm{i}$ \\
\hline & FN07 & Planejamento de cidades inteligentes & & & & & e & & & $\Theta$ & & e & & & & & \\
\hline & FN08 & Planejamento de universidades empreendedoras & & & & $\mathrm{i}$ & & & & & & & & & & & \\
\hline
\end{tabular}

Fonte: Autores (2020)

A Figura 3 apresenta o cruzamento das unidades de contexto e fenômenos, onde assinalou-se com (e) os excluídos da análise e com (i) os incluídos. Nas pesquisas não assinaladas com nenhuma das opções não se identificou ocorrência do fenômeno. Assim, os estudos 5, 9, 10 e 11 foram excluídos da análise. A partir 
destas definições, identificou-se 258 regras de associação, correlação e agrupamento.

A força de uma regra pode ser medida pelo suporte, confiança e lift. $\mathrm{O}$ suporte determina quantas vezes uma regra se aplica a um determinado conjunto de dados, a confiança determina a frequência com que itens " $Y$ " (consequente) aparecem em relacionamentos que contêm " $X$ "(antecedente) e o lift calcula a proporção entre confiança e suporte na regra consequente. Em uma relação de causa e efeito, quanto maior o lift, maior a probabilidade de ocorrência do item consequente quando ocorre o item antecedente (ZHANG, C., ZHANG, 2002). A Figura 4 apresenta a matriz confiança $x$ suporte $x$ lift.

Figura 4 - Matriz confiança $x$ suporte $x$ lift

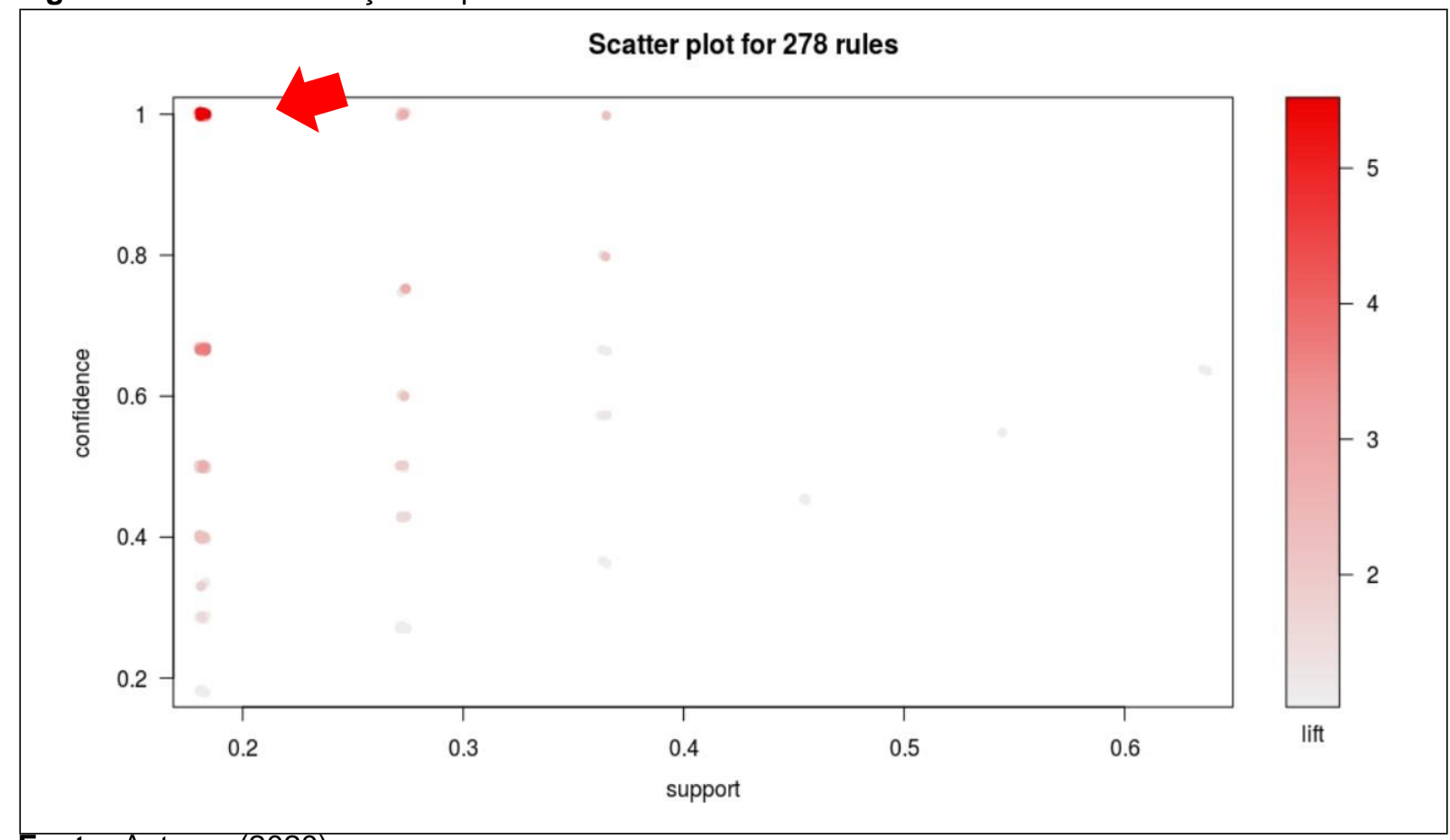

Fonte: Autores (2020)

A Figura 4 apresenta a matriz de confiança x suporte x lift. Quanto maior o lift e a confiança mais forte a relação de causa e efeito entre os itens da regra. Assim, apesar de todas as 258 regras apresentarem lift maior que 1, ou seja, com probabilidade real de ocorrência combinada, apenas os itens com lift maior que 5 e confiança igual a 1 serão analisadas. A Figura 5 apresenta a associação de tais itens. 
Figura 5 - Regras de associação

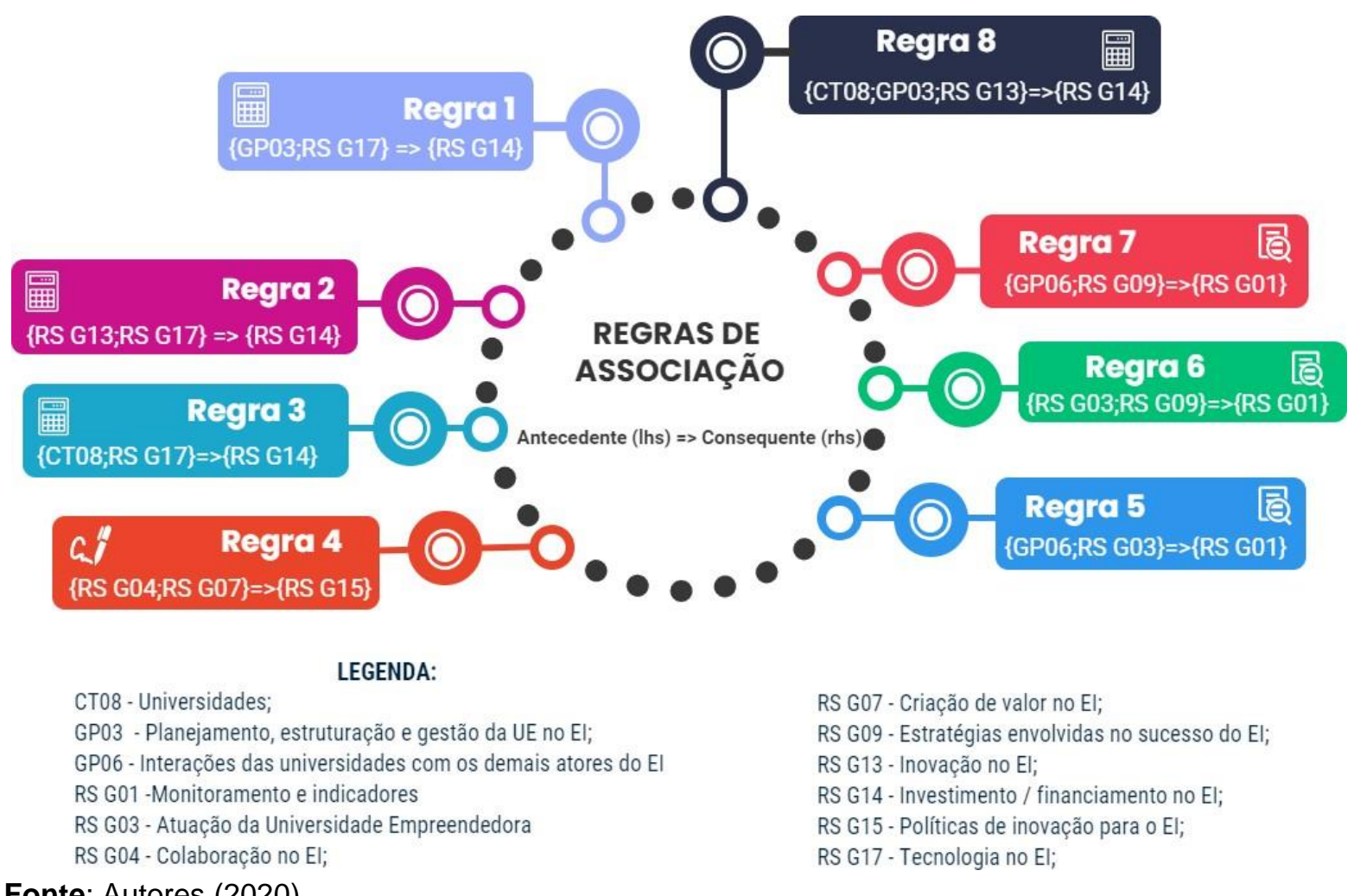

Fonte: Autores (2020)

A Figura 5 demonstra que foram identificadas 8 regras de associação de acordo com critérios estabelecidos. A estruturação de tais regras obedece a parcela antecedente $=>$ parcela consequente. Tais resultados são discutidos a seguir.

\section{DISCUSSÃO DOS RESULTADOS}

Cada uma das 8 regras resultantes indica que há 5,5 vezes mais probabilidade de que, ao ocorrer a parcela consequente da regra, a parcela antecedente também ocorra (lift=5,5). A regra 1 indica RS-G14 conjuntamente com GP03 e combinado com RS-G17. Os resultados relacionados a RS-G14 são descritos como a necessidade das empresas do El de se relacionarem com os órgãos públicos para orquestrar aquisição e gerenciamento de financiamento, incluindo atividades de monitoramento de oportunidades de financiamento alinhadas às demandas internas, bem como estrutura de gerenciamento responsável por prestação de contas e estrutura dedicada à avaliação e uso de incentivos fiscais de acordo com a legislação local (VARRICHIO et al., 2012). Tais aspectos apresentamse ainda quanto aos níveis de investimento locais. As conexões entre universidades 
e indústria no contexto brasileiro ainda são fracas. Os fatores que influenciam a escolha de uma multinacional (com matriz em outros Países) em se instalar em regiões no Brasil parece considerar incubadoras e parques científicos como preditores no estágio de seleção para cidades, mas não para microrregiões. Patentes tem o comportamento oposto. Nenhum desses padrões, no entanto, vale para o estágio final da análise, evidenciando a proposição de que essas empresas são orientadas para estratégias de exploração de ativos quando operam no contexto de países em desenvolvimento (FISCHER; SCHAEFFER; SILVEIRA, 2018). Em todas as vezes que este resultado ocorre, o grupo de problemas abordado é o GP03 combinado com RS-G17 e, quanto aos aspectos tecnológicos, os resultados indicam que o $\mathrm{El}$ deve desenvolver relações entre empresas e co-criação de valor por meio de tecnologias de informação e comunicação.

Em relação a regra 2, RS-G14 ocorre combinado com RS-G17, discutidos anteriormente, e relacionado ao RS-G13. Em relação ao RS-G13, a inovação deve permear toda a organização (DE MOURA FILHO et al., 2019), mas promovê-la na academia requer resiliência e trabalho em rede, o que é um processo lento (VALADARES et al., 2018). Adicionalmente, as universidades devem assumir o protagonismo no processo de desenvolvimento econômico e social, tendo a inovação e seus ambientes como fundamento (AUDY, 2017).

A comunidade científica possui um padrão de comportamento específico e único. Para consolidar e customizar o relacionamento com esta comunidade, a construção de redes de inovação com a comunidade internacional de ciência e tecnologia pode ser fomentada. Isso pode ocorrer, por exemplo, por meio programas que promovam espaços de aprendizagem e construção de relacionamentos efetivos e duradouros entre empresas e instituições (VARRICHIO et al., 2012).

Quanto a promoção da inovação em empresas brasileiras, é necessário desenvolver capacidades inovadoras interorganizacionais (FISCHER; SCHAEFFER; SILVEIRA, 2018). A inovação e sua gestão devem considerar a seleção de parceiros, boas práticas de negociação, estabelecimento de indicadores (VARRICHIO et al., 2012) e o envolvimento de equipes multidisciplinares (DE MOURA FILHO et al., 2019). Os principais resultados dessa forma de coordenação são melhoria contínua dos modelos de parceria, por meio de discussões 
multidisciplinares, e rapidez na implementação dos planos de ação, provenientes de parcerias e fortalecimento do modelo de governança (VARRICHIO et al., 2012). Entretanto, no Brasil, há um gap na formação de conexões entre empresas e universidades (FISCHER; SCHAEFFER; SILVEIRA, 2018).

A regra 3 indica a ocorrência de RS-G14 combinado RS-G17, discutidos anteriormente, quanto o contexto é CT08. O papel emergente de uma UE é focado na inovação e empreendedorismo, o que contribui com a competitividade e o desenvolvimento econômico regional. (AUDRETSCH et al., 2019; GUERRERO et al., 2016).

Segundo a regra 4, RS-G15 ocorre combinado com RS-G04 e RS-G07. Quanto ao RS-G15, para melhorar significativamente as capacidades dos Els são necessárias políticas de incentivos e marcos regulatórios que promovam conexões entre instituições acadêmicas e mercados (FISCHER; SCHAEFFER; SILVEIRA, 2018). Estes incentivos ainda são baixos, mas podem representar uma estratégia promissora para o Sistema Brasileiro de Inovação. Políticas e estratégias de longo prazo contribuem para criação de condições locais para o desenvolvimento regional por meio de Els e tais políticas devem incluir o processo de design, alinhamento às leis regionais, indicadores-chave de sucesso, diretrizes para parcerias e proteção a propriedade intelectual (VARRICHIO et al., 2012).

Em relação ao RS-G04, a parceria entre UEs favorece troca de experiências bem sucedidas (VALADARES et al., 2018). O aprendizado no El pode ser favorecido pela colaboração de tutores do ecossistema local de inovação, priorização da colaboração interorganizacional, foco em sinergias e promoção de conhecimentos, ferramentas e metodologias (VARRICHIO et al., 2012). Entretanto, deve-se considerar que empresas do tipo multinacionais com matriz em outros países, quando operam em mercados emergentes, são menos propensas a envolver-se em relacionamentos colaborativos com universidades (FISCHER; SCHAEFFER; SILVEIRA, 2018).

Em relação ao RS-G07, as motivações podem ser diferentes para UE e o mercado, e até mesmo entre universidades (BENITEZ; AYALA; FRANK, 2020). Diferentes modelos de interação podem ser desenvolvidos, considerando alternativas de viabilidade e retorno do investimento em parcerias, principalmente quando se busca relações de médio e longo prazos. (VARRICHIO et al., 2012). 
Neste sentido, atores devem ter cuidado com expectativas conflitantes. A medida que o ecossistema evolui, novas formas de criação e captação de valor são esperadas, mas devem estar alinhadas com a mudança do EI (BENITEZ; AYALA; FRANK, 2020).

A regra 5 indica RS-G01 ocorre combinada com RS-G03 e GP06. O RS-G01 faz referência a necessidade de indicadores (VARRICHIO et al., 2012), embora não indique especificamente o que estes indicadores devem medir.

Quanto ao RS-G03, a dimensão mais importante de um El é a colaboração universidade-indústria (PEDRINHO et al., 2020). Assim, as UEs devem atuar no sentido de criar e coordenar projetos que beneficiam todo o ecossistema, especialmente no estágio inicial, quando são percebidas como agentes neutros, pois isso favorece a confiança (BENITEZ; AYALA; FRANK, 2020).

O El deve promover estratégias de interação entre governo, indústria e universidades, colocando as UEs no papel de atores centrais no contexto dos Els. (PEDRINHO et al., 2020). Tais vínculos no Brasil são fortemente orientados para projetos de curto prazo, baseados em solução de problemas técnicos imediatos de parceiros industriais. Essas conexões são focadas principalmente nos setores de baixa e média tecnologia (FISCHER; SCHAEFFER; SILVEIRA, 2018).

Os impactos decorrentes do fornecimento de uma força de trabalho "educada" podem ser benéficos para o ambiente de inovação local. No entanto, esses efeitos são mais limitados do que os esperados pela academia. Ainda assim, os principais benefícios da participação de instituições acadêmicas nos Els são locais e, neste sentido, expectativas regionais devem ser ajustadas (SCHAEFFER; FISCHER; QUEIROZ, 2018). Apesar disso, espera-se que as UEs atuem como vetores do desenvolvimento econômico e social da sociedade, promovendo o desenvolvimento de competências voltadas ao empreendedorismo por meio de experiências práticas para os alunos (DE PAULA et al., 2017), desenvolvendo competências relacionadas ao gerenciamento da inovação e inteligência de redes no El por meio de parcerias corporativas (VARRICHIO et al., 2012) e ampliando sua missão básica de ensino e pesquisa, passando a atuar como fonte de resolução de problemas e novas possibilidades (AUDY, 2017).

A regra 6 indica que RS-G01 ocorre combinado com GP06, já discutidos, somado a RS-G09. Os resultados de RS-G09 indicam que é preciso promover 
estratégias de longo prazo para atender as demandas de um cenário tecnológico, econômico e de mudanças rápidas, mas isso pode ser um processo lento (VALADARES et al., 2018). Uma estratégia para avançar em programas de empreendedorismo pode ser viabilizada por meio da internacionalização (VALADARES et al., 2018). Ao mesmo tempo que precisa estabelecer estratégias de logo prazo para implementação de mudanças, as UEs devem preservar os valores da instituição ao definir suas estratégias de atuação (AUDY, 2017). Ainda sobre a estratégia de parcerias, para atrair investimentos locais, é importante estabelecer estratégias acadêmicas que concentram-se no desenvolvimento de canais visando uma aproximação entre academia e mercados (FISCHER; SCHAEFFER; SILVEIRA, 2018). Apesar desta possibilidade, alguns vetores fundamentais não são facilmente manipulados no curto prazo e parece haver importância fundamental atribuída a condições evolutivas de longo prazo (SCHAEFFER; FISCHER; QUEIROZ, 2018). As variáveis das regras 7 e 8 já foram apresentadas e discutidas anteriormente.

\subsection{Fatores críticos de sucesso}

Fatores Críticos de Sucesso (FCS) são as áreas-chave de atividades em que resultados favoráveis são imprescindíveis para o alcance das metas organizacionais (BULLEN; ROCKART, 1981). A análise das regras de associação (figura 4) indica o relacionamento entre as variáveis codificadas por esta pesquisa que, combinadas com os resultados dos estudos analisados, deram origem a 28 FCS propostos por este estudo. A origem de cada FCS, bem como sua descrição são apresentados no Quadro 02. 


\begin{tabular}{|c|c|c|c|}
\hline \multicolumn{2}{|c|}{ ORIGEM } & \multirow[b]{2}{*}{ FCS } & \multirow[b]{2}{*}{ Descrição do FCS } \\
\hline 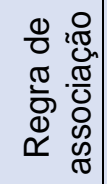 & 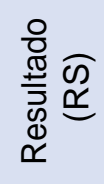 & & \\
\hline 5 & $\begin{array}{l}\text { RS } \\
\text { G01 }\end{array}$ & 1 & Indicadores-chave de desempenho devem ser estabelecidos. \\
\hline 5 & $\begin{array}{l}\text { RS } \\
\text { G03 }\end{array}$ & 2 & $\begin{array}{l}\text { UEs devem atuar na criação e coordenação de projetos que beneficiam todo } \\
\text { o El, especialmente no estágio inicial. }\end{array}$ \\
\hline 5 & $\begin{array}{l}\text { RS } \\
\text { G03 }\end{array}$ & 3 & As UEs devem atuar como impulsionadoras para atração de investimentos. \\
\hline 5 & $\begin{array}{l}\text { RS } \\
\text { G03 }\end{array}$ & 4 & $\begin{array}{l}\text { Os efeitos dos impactos decorrentes do fornecimento de mão de obra } \\
\text { qualificada são muito mais limitados do que os esperados pela academia. }\end{array}$ \\
\hline 5 & $\begin{array}{l}\text { RS } \\
\text { G03 }\end{array}$ & 5 & $\begin{array}{l}\text { O desenvolvimento de competências voltadas ao empreendedorismo pode } \\
\text { ocorrer por meio de experiências práticas para os alunos. }\end{array}$ \\
\hline 5 & $\begin{array}{l}\text { RS } \\
\text { G03 }\end{array}$ & 6 & $\begin{array}{l}\text { Para assumirem como vetores do desenvolvimento econômico e social da } \\
\text { sociedade, UEs devem incluir competências relacionadas ao gerenciamento } \\
\text { da inovação aberta e à inteligência de redes no El por meio de parcerias } \\
\text { com universidades e parcerias corporativas. }\end{array}$ \\
\hline 4 & $\begin{array}{l}\text { RS } \\
\text { G04 }\end{array}$ & 7 & $\begin{array}{l}\text { Para assumirem como vetores do desenvolvimento econômico e social da } \\
\text { sociedade, UEs devem incluir competências relacionadas ao gerenciamento } \\
\text { da inovação aberta e à inteligência de redes no El por meio de parcerias } \\
\text { com universidades e parcerias corporativas. }\end{array}$ \\
\hline 4 & $\begin{array}{l}\text { RS } \\
\text { G04 }\end{array}$ & 8 & $\begin{array}{l}\text { Ações focando em sinergias, promoção conhecimentos, ferramentas e } \\
\text { metodologias devem ser priorizadas para obtenção da colaboração } \\
\text { interorganizacional. }\end{array}$ \\
\hline 4 & $\begin{array}{l}\text { RS } \\
\text { G04 }\end{array}$ & 9 & $\begin{array}{l}\text { Empresas multinacionais com matriz em outros países são menos } \\
\text { propensas a relacionamentos colaborativos e, portanto, com menor interesse } \\
\text { na geração de valor para o El. }\end{array}$ \\
\hline 4 & $\begin{array}{l}\text { RS } \\
\text { G07 }\end{array}$ & 10 & $\begin{array}{l}\text { O desenvolvimento regional por meio de ecossistemas de inovação } \\
\text { necessita de estratégias de longo prazo para criação de valor. }\end{array}$ \\
\hline 4 & $\begin{array}{l}\text { RS } \\
\text { G07 }\end{array}$ & 11 & $\begin{array}{l}\text { Para criação de valor no El é preciso identificar as diferentes motivações. } \\
\text { UEs e mercado tem motivações diferentes para participação em Els. Entre } \\
\text { universidades também pode haver diferentes estímulos. }\end{array}$ \\
\hline 4 & $\begin{array}{l}\text { RS } \\
\text { G07 }\end{array}$ & 12 & $\begin{array}{l}\text { A captação de valor esperada pelos membros do El devem estar alinhadas a } \\
\text { com as mudanças decorrentes da evolução do ecossistema. }\end{array}$ \\
\hline 6 & $\begin{array}{l}\text { RS } \\
\text { G09 }\end{array}$ & 13 & $\begin{array}{l}\text { Estratégias de longo prazo em relação a participação de UEs em programas } \\
\text { globais, captação de investimentos, manutenção de aspectos culturais e } \\
\text { valores essenciais, abertura de novos campi e estágios de transição devem } \\
\text { ser definidas. }\end{array}$ \\
\hline 2 & $\begin{array}{l}\text { RS } \\
\text { G13 }\end{array}$ & 14 & $\begin{array}{l}\text { Promover a inovação na academia é um processo lento que requer } \\
\text { resiliência e trabalho em rede, pois representa uma mudança na cultura e } \\
\text { nos valores. }\end{array}$ \\
\hline 2 & $\begin{array}{l}\text { RS } \\
\text { G13 }\end{array}$ & 15 & $\begin{array}{l}\text { Para inovar as universidades devem assumir um papel protagonista no } \\
\text { processo de desenvolvimento econômico e social, tendo a inovação e os } \\
\text { ambientes de inovação como fundamento. }\end{array}$ \\
\hline 2 & $\begin{array}{l}\text { RS } \\
\text { G13 }\end{array}$ & 16 & $\begin{array}{l}\text { Para customizar consolidar o relacionamento com a comunidade científica, } \\
\text { um ambiente de construção de redes de inovação com a comunidade } \\
\text { mundial de ciência e tecnologia pode ser fomentado. }\end{array}$ \\
\hline 2 & $\begin{array}{c}\text { RS } \\
\text { G13 }\end{array}$ & 17 & $\begin{array}{l}\text { A inovação e sua gestão devem ser gerenciadas como um processo que } \\
\text { envolve diversas áreas organizacionais, formando equipes multidisciplinares }\end{array}$ \\
\hline
\end{tabular}




\begin{tabular}{|c|c|c|c|}
\hline \multicolumn{2}{|c|}{ ORIGEM } & \multirow[b]{2}{*}{ FCS } & \multirow[b]{2}{*}{ Descrição do FCS } \\
\hline 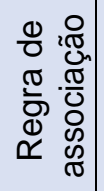 & 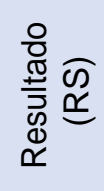 & & \\
\hline 2 & $\begin{array}{l}\text { RS } \\
\text { G13 }\end{array}$ & 18 & $\begin{array}{l}\text { É preciso considerar a baixa tendência das empresas para pesquisa e } \\
\text { desenvolvimento }(P \& D) \text { interno. }\end{array}$ \\
\hline 3 & $\begin{array}{l}\text { RS } \\
\text { G13 }\end{array}$ & 19 & $\begin{array}{l}\text { UEs contribuem com a competitividade e devem ser consideradas para } \\
\text { fomentar o desenvolvimento regional. }\end{array}$ \\
\hline 1 & $\begin{array}{l}\text { RS } \\
\text { G14 }\end{array}$ & 20 & $\begin{array}{l}\text { Relacionamento de forma constante com os órgãos públicos, incluindo } \\
\text { atividades de monitoramento de novas oportunidades de financiamento, } \\
\text { devem estar alinhadas às demandas internas. }\end{array}$ \\
\hline 1 & $\begin{array}{l}\text { RS } \\
\text { G14 }\end{array}$ & 21 & $\begin{array}{l}\text { Deve-se estabelecer uma estrutura de gerenciamento responsável pelos } \\
\text { relatórios técnicos e financeiros de prestação de contas, com uma estrutura } \\
\text { dedicada à avaliação e uso de incentivos fiscais de acordo com a legislação } \\
\text { local. }\end{array}$ \\
\hline 1 & $\begin{array}{l}\text { RS } \\
\text { G14 }\end{array}$ & 22 & $\begin{array}{l}\text { É preciso fortalecer as conexões entre universidades e indústria no contexto } \\
\text { brasileiro, que ainda são fracas. }\end{array}$ \\
\hline 1 & $\begin{array}{l}\text { RS } \\
\text { G14 }\end{array}$ & 23 & $\begin{array}{l}\text { No âmbito das cidades, para atrair a atenção de investidores internacionais } \\
\text { relacionados a empresas com matriz em outros países, é preciso fomentar a } \\
\text { existência de incubadoras e parques científicos, que são consideradas } \\
\text { como provedores de conhecimento de alto nível e estão vinculados às } \\
\text { universidades, embora este não seja o principal elemento para tomada de } \\
\text { decisão quanto ao local onde estes investimentos, de fato, devem ocorrer. }\end{array}$ \\
\hline 1 & $\begin{array}{l}\text { RS } \\
\text { G14 }\end{array}$ & 24 & $\begin{array}{l}\text { No âmbito de microrregião, para atrair atenção dos investidores, registros de } \\
\text { patentes e modelos de utilidade devem ser fomentados. As UEs devem } \\
\text { pensar em uma estratégia de incentivo aos pesquisadores neste sentido. No } \\
\text { entanto, estes padrões, no entanto, estes padrões não valem para o estágio } \\
\text { final da análise. }\end{array}$ \\
\hline 4 & $\begin{array}{l}\text { RS } \\
\text { G15 }\end{array}$ & 25 & $\begin{array}{l}\text { Políticas voltadas a incentivos e marcos regulatórios que promovam } \\
\text { conexões mais estreitas entre instituições acadêmicas e mercados } \\
\text { melhoram significativamente a geração de valor e capacidades do El. }\end{array}$ \\
\hline 4 & $\begin{array}{l}\text { RS } \\
\text { G15 }\end{array}$ & 26 & $\begin{array}{l}\text { Promover interações mais estreitas entre UEs e sistemas comerciais pode } \\
\text { impulsionar a inovação tecnológica. }\end{array}$ \\
\hline 4 & $\begin{array}{l}\text { RS } \\
\text { G15 }\end{array}$ & 27 & $\begin{array}{l}\text { É necessário definir os limites geográficos do El para definição das políticas } \\
\text { de inovação que favoreçam a geração e captação de valor pelo } \\
\text { ecossistema. }\end{array}$ \\
\hline 1 & $\begin{array}{l}\text { RS } \\
\text { G15 }\end{array}$ & 28 & $\begin{array}{l}\text { O El deve desenvolver relações entre as empresas e co-criação de valor por } \\
\text { meio de tecnologias de informação e comunicação. }\end{array}$ \\
\hline
\end{tabular}

Fonte: autores (2020)

Conforme apresenta o Quadro 02, os FCS foram numerados, totalizando 28 FCS, tendo como origem em uma das regras de associação, já discutidas, e nos resultados identificados a partir da análise das unidades de contexto que compõe esta pesquisa, apresentados no Apêndice B. Os objetivos em comum de tais FCS permitiu ainda seu agrupamento, dando origem a 9 grupos (FCS G) distintos, embora complementares. A Figura 6 apresenta agrupamento proposto por esta pesquisa. 
Figura 6 - Fatores críticos de sucesso

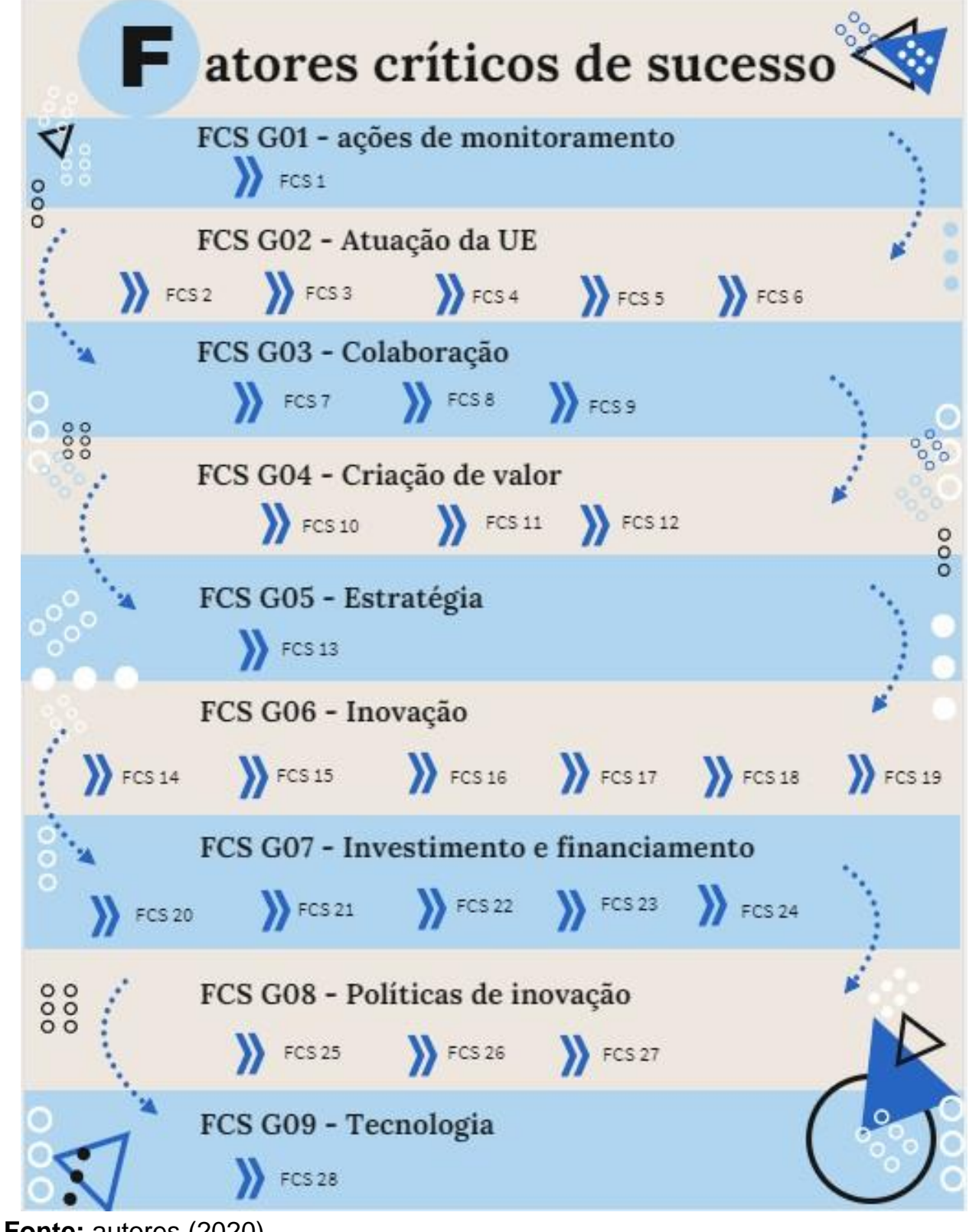

Fonte: autores (2020)

Conforme apresentado na Figura 6, os 28 FCS foram agrupados de acordo com seu objetivo, resultando em 9 agrupamentos. Os grupos de FCS identificados identificaram que as UEs devem ter clareza quanto a sua atuação no El (FCS-G02), promovendo ações relativas ao estabelecimento de indicadores-chave (FCS-G01), promoção da inovação (FCS-G06), colaboração (FCS-G03) e criação de valor para o ecossistema (FCS-G04). Além disso, a UE deve considerar seu papel na promoção de políticas públicas (FCS-G08) e captação de investimentos para o El (FCS-G07). De forma complementar, a universidade deve pensar em estratégias de longo prazo que viabilizem o engajamento interno e o alinhamento da estratégia do negócio e do 
El (FCS-G05), além de promover o uso e desenvolvimento de tecnologias de comunicação (FCS-G09). Desta forma, os FCS identificados nesta pesquisa representam um caminho a ser percorrido pelas UEs que atuem ou desejem atuar a partir do contexto de Els. Considerando o alinhamento de tais FCS, pode-se identificar as demandas gerenciais e planejar as ações estratégicas, táticas e operacionais para criação, inserção ou adequação, bem como rever seu modelo de atuação no El.

\section{CONSIDERAÇÕES FINAIS}

Esta pesquisa abordou o mapeamento e análise dos estudos conduzidos pela comunidade científica brasileira, identificando e definindo os FCS para implementação da UE. Por meio das regras de associação, a análise das relações ocultas de causa e efeito indicaram que 8 regras de associação dão origem a 28 FCS que devem ser considerados para as universidades obterem sucesso no contexto de El. A partir destes fatores, as universidades podem identificar as demandas e planejar as ações estratégicas para criação, inserção ou adequação, bem como rever seu modelo de atuação no El.

Estudos futuros são sugeridos para analisar as demais regras de associação que emergem desta pesquisa. Apenas as regras de associação de maior força foram incluídas nesta análise, o que se constitui em uma limitação da pesquisa e oportunidade de estudos adicionais. Da mesma forma, a ampliação do escopo, incluindo outras bases de dados e estudos em outros países podem constituir-se em oportunidades de estudos futuros, além de estudos empíricos que validem as proposições dos FCS identificados por esta pesquisa. Adicionalmente, estudos podem ser desenvolvidos para analisar as relações de causa e efeito entre os FCS identificados por esta pesquisa, bem como que promovam a proposição de um check list que identifique o grau de alinhamento entre os processos da UE em relação aos FCS identificados. 


\section{AGRADECIMENTOS}

Os autores agradecem as contribuições do Prof. Me. Leandro Gauss (ID Lattes: 8209657938986583) e Profa. Me. Ana Paula Ermel (ID Lattes: 0246748335398590) e agradecem também ao Conselho Nacional de Desenvolvimento Científico e Tecnológico (CNPq) e à Coordenação para o Aperfeiçoamento do Pessoal de Ensino Superior (CAPES) pelo apoio recebido para conduzir esta pesquisa. Processo no-88887.343305/2019-00.

\section{REFERÊNCIAS}

ADNER, R. Match your innovation strategy to your innovation ecosystem. Harvard Business Review, v. 84, n. 4, p. 98-148, 2006.

AUDRETSCH, D. B. et al. Entrepreneurial ecosystems: economic, technological, and societal impacts. Journal of Technology Transfer, v. 44, n. 2, p. 313-325, 2019. https://doi.org/10.1007/s10961-018-9690-4

AUDY, J. A inovação, o desenvolvimento e o papel da Universidade. [S. I.: s. n.], 2017. Disponível em: https://doi.org/10.1590/s0103-40142017.3190005

BENITEZ, G. B.; AYALA, N. F.; FRANK, A. G. Industry 4.0 innovation ecosystems: An evolutionary perspective on value cocreation. International Journal of Production Economics, v. 228, 2020. https://doi.org/10.1016/.i.jpe.2020.107735

BULLEN, C. V.; ROCKART, J. F. A primer on critical success factors. Working papers, n. 69, p. 1-64, 1981.

CLARYSSE, B. et al. Creating value in ecosystems: Crossing the chasm between knowledge and business ecosystems. Research Policy, v. 43, n. 7, p. 1164-1176, 2014.

https://doi.org/10.1016/j.respol.2014.04.014

DE MOURA FILHO, S. L. et al. Entrepreneurial university - a method of evaluation and planning applied in Brazil. Revista gestao \& tecnologia-journal of management and technology, v. 19, n. 1, p. 159-184, 2019. https://doi.org/10.20397/2177-

6652/2019.v19i1.1514

DE PAULA, I. C. et al. Innovation ecosystems in engineering education: From local experiences to a vision of the future. In: ANNUAL CONFERENCE AND EXPO OF THE INSTITUTE OF INDUSTRIAL ENGINEERS, 67,. 2017. [Proceedings...]. Institute of Industrial Engineers, 2017. p. 1412-1418.

DRESCH, A., LACERDA, D. P., JÚNIOR, J. A. V. A. Design science research: a method for science and technology advancement. New York: Springer, 2015.

ERMEL, A. P. C. Literature grounded theory: método de pesquisa para investigação sobre o conhecimento científico e tecnológico, 2020. Dissertação (Mestrado) - Programa de PósGraduação em Engenharia de Produção e Sistemas. Universidade do Vale do Rio dos Sinos, 2020.

Revista Produção Online. Florianópolis, SC, v. 21, n. 1, p. 105-130, 2021. 
ETZKOWITZ, H.; LEYDESDORFF, L. The dynamics of innovation: From National Systems and "mode 2" to a Triple Helix of university-industry-government relations. Research Policy, v. 29, n. 2, p. 109-123, 2000. https://doi.org/10.1016/S0048-7333(99)00055-4

FISCHER, B. B.; SCHAEFFER, P. R.; SILVEIRA, J. P. Universities' gravitational effects on the location of knowledge-intensive investments in Brazil. Science and Public Policy, v. 45, n. 5, p. 692-707, 2018. https://doi.org/10.1093/SCIPOL/SCY002

GUERRERO, M. et al. Entrepreneurial universities: emerging models in the new social and economic landscape. Small Business Economics, v. 47, n. 3, p. 551-563, 2016. https://doi.org/10.1007/s11187-016-9755-4

HAYTER, C. S. A trajectory of early-stage spinoff success: the role of knowledge intermediaries within an entrepreneurial university ecosystem. Small Business Economics, v. 47, n. 3, p. 633-656, 2016. https://doi.org/10.1007/s11187-016-9756-3

MARKKULA, MARKKU; KUNE, H. Making smart regions smarter: smart specialization and the role of universities in regional innovation ecosystems. Technology Innovation Management Review, v. 5, n. 10, 2015.

MOORE, G. A. Crossing the chasm: marketing and selling high-tech products to mainstream consumers. New York: NY, 1991.

MOORE, J. F. Predators and prey: a new ecology of competition. Harvard Business Review, v. 71, n. 3, p. 75-86, 1993.

MORANDI, M. I. W. M.; CAMARGO, L. F. R. Revisão sistemática da literatura. In: DESIGN SCIENCE RESEARCH: A METHOD FOR SCIENCE AND TECHNOLOGY ADVANCEMENT, 2015. [Proceedings...] New York: Springer, 2015.

NAMBISAN, S.; BARON, R. A. Entrepreneurship in innovation ecosystems: Entrepreneurs' self-regulatory processes and their implications for new venture success. Entrepreneurship: Theory and Practice, v. 37, n. 5, p. 1071-1097, 2013. https://doi.org/10.1111/j.1540$\underline{6520.2012 .00519 . x}$

PEDRINHO, G. C. et al. Universidade e o ecossistema de inovação: revisão estruturada de literatura. Navus - Revista de Gestão e Tecnologia, v. 10, p. 01-23, 2020. https://doi.org/10.22279/navus.2020.v10.p01-23.955

SCHAEFFER, P. R.; FISCHER, B.; QUEIROZ, S. Beyond education: The role of research universities in innovation ecosystems. Foresight and STI Governance, v. 12, n. 2, p. 50-61, 2018. https://doi.org/10.17323/2500-2597.2018.2.50.61

SHAW, D. R.; ALLEN, T. Studying innovation ecosystems using ecology theory. Technological Forecasting and Social Change, 2016.

VALADARES, E. C. et al. Work in progress: Fostering synergy to create an innovation environment. In: IEEE GLOBAL ENGINEERING EDUCATION CONFERENCE, EDUCON, 2018. [Proceedings ...]. IEEE Computer Society, 2018. p. 1-3.

https://doi.org/10.1109/EDUCON.2018.8363099

VARRICHIO, P. et al. Collaborative Networks and Sustainable Business: A Case Study in the Brazilian System of Innovation. Procedia - Social and Behavioral Sciences, v. 52, p. 90-99, 2012. https://doi.org/10.1016/j.sbspro.2012.09.445 
YAGHMAIE, P.; VANHAVERBEKE, W. Identifying and describing constituents of innovation ecosystems: A systematic review of the literature. EuroMed Journal of Business, [s. I.], v. ahead-of-p, 2019. https://doi.org/10.1108/EMJB-03-2019-0042

ZHANG, C., ZHANG, S. Association Rule Mining. Berlin, Heidelberg: Springer Berlin Heidelberg, 2002. (Lecture Notes in Computer Science).v. 2307. https://doi.org/10.1007/3540-46027-6

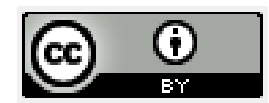

Artigo recebido em: 22/11/2020 e aceito para publicação em: 04/03/2021

DOI: http://dx.doi.org/10.14488/1676-1901.v21i1.4174 
APÊNDICE A - Codificação

(continua)

\begin{tabular}{|c|c|c|c|c|c|}
\hline $\begin{array}{l}\text { Número } \\
\text { do } \\
\text { código }\end{array}$ & Grupo & $\begin{array}{l}\text { Descrição do } \\
\text { grupo }\end{array}$ & $\begin{array}{l}\text { Nome } \\
\text { do } \\
\text { código }\end{array}$ & $\begin{array}{l}\text { Tipo de } \\
\text { código }\end{array}$ & Descrição do código \\
\hline 1 & \multirow{5}{*}{ AN } & \multirow{5}{*}{$\begin{array}{l}\text { Ano da } \\
\text { publicação }\end{array}$} & AN01 & aberto & 2012 \\
\hline 2 & & & AN02 & aberto & 2017 \\
\hline 3 & & & AN03 & aberto & 2018 \\
\hline 4 & & & AN04 & aberto & 2019 \\
\hline 5 & & & AN05 & aberto & 2020 \\
\hline 6 & CB & $\begin{array}{l}\text { Contribuições } \\
\text { da pesquisa }\end{array}$ & CB & fechado & $\begin{array}{l}\text { Contribuições da pesquisa definidas } \\
\text { pelos autores }\end{array}$ \\
\hline 7 & \multirow{9}{*}{ CT } & \multirow{9}{*}{ Contexto } & CT01 & aberto & Cidade específica \\
\hline 8 & & & CT02 & aberto & Ecossistema hipotético \\
\hline 9 & & & CT03 & aberto & Cross countries \\
\hline 10 & & & CT04 & aberto & Empresa específica \\
\hline 11 & & & CT05 & aberto & PME's indústria 4.0 \\
\hline 12 & & & СT06 & aberto & Sociedade do conhecimento \\
\hline 13 & & & CT07 & aberto & Startup \\
\hline 14 & & & СT08 & fechado & Universidades \\
\hline 15 & & & СT09 & fechado & Não se aplica \\
\hline 16 & \multirow{7}{*}{ FCS } & \multirow{7}{*}{$\begin{array}{l}\text { Fatores } \\
\text { críticos de } \\
\text { Sucesso }\end{array}$} & $\begin{array}{l}\text { FCS } \\
\text { G01 }\end{array}$ & aberto & $\begin{array}{l}\text { Ações de monitoramento e } \\
\text { indicadores }\end{array}$ \\
\hline 17 & & & $\begin{array}{l}\text { FCS } \\
\text { G02 }\end{array}$ & aberto & $\begin{array}{l}\text { Atuação da Universidade } \\
\text { Empreendedora }\end{array}$ \\
\hline 18 & & & $\begin{array}{l}\text { FCS } \\
\text { G03 }\end{array}$ & aberto & $\begin{array}{l}\text { Aspectos relacionados a colaboração } \\
\text { ecossistema de inovação }\end{array}$ \\
\hline 19 & & & $\begin{array}{l}\text { FCS } \\
\text { G04 }\end{array}$ & aberto & $\begin{array}{l}\text { Aspectos relacionados a criação de } \\
\text { valor no ecossistema de inovação }\end{array}$ \\
\hline 20 & & & $\begin{array}{l}\text { FCS } \\
\text { G05 }\end{array}$ & aberto & $\begin{array}{l}\text { Aspectos relacionados a estratégias } \\
\text { envolvidas no sucesso do } \\
\text { ecossistema de inovação }\end{array}$ \\
\hline 21 & & & $\begin{array}{l}\text { FCS } \\
\text { G06 }\end{array}$ & aberto & $\begin{array}{l}\text { Aspectos relacionados a gestão do } \\
\text { relacionamento no ecossistema de } \\
\text { inovação }\end{array}$ \\
\hline 22 & & & $\begin{array}{l}\text { FCS } \\
\text { G07 }\end{array}$ & aberto & $\begin{array}{l}\text { Aspectos relacionados ao } \\
\text { Investimento / financiamento no } \\
\text { ecossistema de inovação }\end{array}$ \\
\hline
\end{tabular}




\begin{tabular}{|c|c|c|c|c|c|}
\hline $\begin{array}{l}\text { Número } \\
\text { do } \\
\text { código }\end{array}$ & $\begin{array}{c}\text { Grup } \\
0\end{array}$ & $\begin{array}{l}\text { Descrição } \\
\text { do grupo }\end{array}$ & $\begin{array}{l}\text { Nome } \\
\text { do } \\
\text { código }\end{array}$ & $\begin{array}{l}\text { Tipo } \\
\text { de } \\
\text { código }\end{array}$ & Descrição do código \\
\hline 23 & & & $\begin{array}{l}\text { FCS } \\
\text { G08 }\end{array}$ & aberto & $\begin{array}{l}\text { Aspectos relacionados a Políticas de } \\
\text { inovação para o ecossistema de } \\
\text { inovação }\end{array}$ \\
\hline 24 & & & $\begin{array}{l}\text { FCS } \\
\text { G09 }\end{array}$ & aberto & $\begin{array}{l}\text { Aspectos relacionados a tecnologia no } \\
\text { ecossistema de inovação }\end{array}$ \\
\hline 25 & \multirow{8}{*}{ FN } & \multirow{8}{*}{ Fenômeno } & FN01 & aberto & $\begin{array}{l}\text { Contribuições das Startups para } \\
\text { inovação digital (4.0) }\end{array}$ \\
\hline 26 & & & FN02 & aberto & $\begin{array}{l}\text { Desdobramentos da presença das } \\
\text { universidades no El }\end{array}$ \\
\hline 27 & & & FN03 & aberto & Evolução dos El \\
\hline 28 & & & FN04 & aberto & $\begin{array}{l}\text { Gestão do relacionamento da rede de } \\
\text { colaboração do El }\end{array}$ \\
\hline 29 & & & FN05 & aberto & $\begin{array}{l}\text { Captação e retenção de alunos no } \\
\text { ensino superior }\end{array}$ \\
\hline 30 & & & FN06 & aberto & $\begin{array}{l}\text { Inovações disruptivas na educação } \\
\text { superior }\end{array}$ \\
\hline 31 & & & FN07 & aberto & Planejamento de cidades inteligentes \\
\hline 32 & & & FN08 & aberto & $\begin{array}{l}\text { Planejamento de universidades } \\
\text { empreendedoras }\end{array}$ \\
\hline 33 & \multirow{6}{*}{ GP } & \multirow{6}{*}{$\begin{array}{l}\text { Grupo de } \\
\text { Problemas } \\
\text { abordado } \\
\text { pela } \\
\text { pesquisa }\end{array}$} & GP01 & aberto & $\begin{array}{l}\text { ATORES - Atuação de startups } \\
\text { incubadas em universidade } \\
\text { empreendedora no ecossistema de } \\
\text { inovação }\end{array}$ \\
\hline 34 & & & GP02 & aberto & $\begin{array}{l}\text { Função / papel do ecossistema na } \\
\text { sociedade }\end{array}$ \\
\hline 35 & & & GP03 & $\begin{array}{c}\text { fechad } \\
0\end{array}$ & $\begin{array}{l}\text { Planejamento, estruturação e gestão } \\
\text { da universidade empreendedora no } \\
\text { ecossistema de inovação }\end{array}$ \\
\hline 36 & & & GP04 & aberto & $\begin{array}{l}\text { Planejamento, estruturação e gestão } \\
\text { de cidades inteligentes (smart cities) }\end{array}$ \\
\hline 37 & & & GP05 & $\begin{array}{c}\text { fechad } \\
0\end{array}$ & $\begin{array}{l}\text { Planejamento, estruturação e gestão } \\
\text { de ecossistemas de inovação }\end{array}$ \\
\hline 38 & & & GP06 & $\begin{array}{c}\text { fechad } \\
0\end{array}$ & $\begin{array}{l}\text { Resultados e relacionamento das } \\
\text { universidades com os demais atores } \\
\text { do ecossistema de inovação }\end{array}$ \\
\hline 39 & \multirow{3}{*}{ IT } & \multirow{3}{*}{$\begin{array}{l}\text { Instituições } \\
\text { dos autores }\end{array}$} & IT01 & aberto & $\begin{array}{l}\text { Universidade Federal de Minas Gerais } \\
\text { - UFMG }\end{array}$ \\
\hline 40 & & & IT02 & aberto & $\begin{array}{l}\text { Universidade Federal do Rio Grande } \\
\text { do Sul - UFRGS }\end{array}$ \\
\hline 41 & & & IT03 & aberto & $\begin{array}{l}\text { Universidade Federal Fluminense - } \\
\text { UFF }\end{array}$ \\
\hline
\end{tabular}




\begin{tabular}{|c|c|c|c|c|c|}
\hline $\begin{array}{l}\text { Número do } \\
\text { código }\end{array}$ & Grupo & $\begin{array}{l}\text { Descrição } \\
\text { do grupo }\end{array}$ & $\begin{array}{l}\text { Nome do } \\
\text { código }\end{array}$ & $\begin{array}{l}\text { Tipo de } \\
\text { código }\end{array}$ & Descrição do código \\
\hline 42 & & & IT04 & aberto & Natura Inovação Tecnol Prod \\
\hline 43 & & & IT05 & aberto & $\begin{array}{l}\text { Pontifícia Universidade Católica do } \\
\text { Paraná - PUC }\end{array}$ \\
\hline 44 & & & IT06 & aberto & $\begin{array}{l}\text { Pontifícia Universidade Católica do } \\
\text { Rio Grande do Sul - PUC }\end{array}$ \\
\hline 45 & & & IT07 & aberto & $\begin{array}{l}\text { Universidade de Campinas - } \\
\text { UNICAMP }\end{array}$ \\
\hline 46 & & & IT08 & aberto & $\begin{array}{l}\text { Universidade Federal da Bahia - } \\
\text { UFBA }\end{array}$ \\
\hline 47 & & & IT09 & aberto & $\begin{array}{l}\text { Universidade Federal de Santa Catarina } \\
\text { - UFSC }\end{array}$ \\
\hline 48 & & & IT10 & aberto & $\begin{array}{l}\text { Universidade Federal do Oeste do Pará - } \\
\text { UFOPA }\end{array}$ \\
\hline 49 & & & IT11 & aberto & $\begin{array}{l}\text { Universidade Federal do Rio Grande do } \\
\text { Norte - UFRN }\end{array}$ \\
\hline 50 & & & IT12 & aberto & Universidade Nova de Lisboa \\
\hline 51 & & & IT13 & aberto & University of Pittsburgh \\
\hline 52 & \multirow{12}{*}{ RS } & \multirow{12}{*}{ Resultados } & RS G01 & aberto & Ações de monitoramento e indicadores \\
\hline 53 & & & RS G02 & aberto & $\begin{array}{l}\text { Aspectos culturais envolvidos no } \\
\text { sucesso do ecossistema de inovação }\end{array}$ \\
\hline 54 & & & RS G03 & aberto & $\begin{array}{l}\text { Atuação da Universidade } \\
\text { Empreendedora }\end{array}$ \\
\hline 55 & & & RS G04 & aberto & $\begin{array}{l}\text { Aspectos relacionados a colaboração } \\
\text { ecossistema de inovação }\end{array}$ \\
\hline 56 & & & RS G05 & aberto & $\begin{array}{l}\text { Aspectos relacionados ao } \\
\text { comprometimento entre os membros no } \\
\text { ecossistema de inovação }\end{array}$ \\
\hline 57 & & & RS G06 & aberto & $\begin{array}{l}\text { Aspectos relacionados a confiança entre } \\
\text { os membros no Ecossistema de } \\
\text { Inovação }\end{array}$ \\
\hline 58 & & & RS G07 & aberto & $\begin{array}{l}\text { Aspectos relacionados a criação de valor } \\
\text { no ecossistema de inovação }\end{array}$ \\
\hline 59 & & & RS G08 & aberto & $\begin{array}{l}\text { Aspectos relacionados a economia do } \\
\text { conhecimento }\end{array}$ \\
\hline 60 & & & RS G09 & aberto & $\begin{array}{l}\text { Aspectos relacionados a estratégias } \\
\text { envolvidas no sucesso do ecossistema } \\
\text { de inovação }\end{array}$ \\
\hline 61 & & & RS G10 & aberto & $\begin{array}{l}\text { Aspectos relacionados a gestão do } \\
\text { relacionamento no ecossistema de } \\
\text { inovação }\end{array}$ \\
\hline 62 & & & RS G11 & aberto & $\begin{array}{l}\text { Aspectos relacionados a governança e } \\
\text { relações de poder no ecossistema de } \\
\text { inovação }\end{array}$ \\
\hline 63 & & & RS G12 & aberto & $\begin{array}{l}\text { Aspectos relacionados a infraestrutura } \\
\text { do ecossistema de inovação }\end{array}$ \\
\hline
\end{tabular}




\begin{tabular}{|c|c|c|c|c|c|}
\hline $\begin{array}{l}\text { Número } \\
\text { do } \\
\text { código }\end{array}$ & Grupo & $\begin{array}{l}\text { Descrição do } \\
\text { grupo }\end{array}$ & $\begin{array}{l}\text { Nome do } \\
\text { código }\end{array}$ & $\begin{array}{l}\text { Tipo de } \\
\text { código }\end{array}$ & Descrição do código \\
\hline 64 & & & RS G13 & aberto & $\begin{array}{l}\text { Aspectos relacionados a inovação } \\
\text { ecossistema de inovação }\end{array}$ \\
\hline 65 & & & RS G14 & aberto & $\begin{array}{l}\text { Aspectos relacionados ao Investimento / } \\
\text { financiamento no ecossistema de } \\
\text { inovação }\end{array}$ \\
\hline 66 & & & RS G15 & aberto & $\begin{array}{l}\text { Aspectos relacionados a Políticas de } \\
\text { inovação para o ecossistema de } \\
\text { inovação }\end{array}$ \\
\hline 67 & & & RS G16 & aberto & $\begin{array}{l}\text { Aspectos relacionados a Recursos } \\
\text { humanos no ecossistema de inovação }\end{array}$ \\
\hline 68 & & & RS G17 & aberto & $\begin{array}{l}\text { Aspectos relacionados a tecnologia no } \\
\text { ecossistema de inovação }\end{array}$ \\
\hline 69 & \multirow{2}{*}{ TP } & \multirow{2}{*}{$\begin{array}{l}\text { Tipo de } \\
\text { estudo }\end{array}$} & TE01 & fechado & Pesquisa bibliográfica \\
\hline 70 & & & TE02 & fechado & Estudo de caso \\
\hline
\end{tabular}

Fonte: Autores (2020) 